\title{
Characterization of Fire Suppression of an Idealized Commodity Using Uniform Water Fluxes
}

\author{
YIBING XIN, KARL V. MEREDITH \\ Research Division \\ FM Global \\ 1151 Boston-Providence Turnpike \\ Norwood, MA 02062, USA
}

\begin{abstract}
An experimental study was conducted to investigate fire suppression behaviors of an idealized commodity using uniform water fluxes. The objectives of this work are to better understand the physics of sprinkler suppression and to provide validation data for numerical fire modeling. The commodities used in the experiments consisted of corrugated cardboard boxes with a metal liner inside. The cardboard boxes were supported by steel beams to maintain the rack storage geometry similar to the standard commodity where wood pallets supported the cardboard boxes. The uniform water fluxes were generated by a water application apparatus (WAA), and adjusted to achieve uncontrolled and controlled fire scenarios. All fire tests were carried out in rack storage configurations with controlled fuel moisture content to minimize its impact on fire growth. The key measurements included heat release rate (HRR), fuel surface temperature, incident heat flux to the fuel surface and water flow rate transported to the bottom of the fuel array. The test results show that the measured heat release rates under various experimental conditions are very repeatable, and thus are suitable for model validation purposes. The fire test outcomes, i.e., controlled vs. uncontrolled fires, are directly correlated with the amount of water collected during the suppression stage, indicating that the sprinkler suppression mechanism is dominated by water transport in the fuel array. The idealized commodity exhibited fire growth rates similar to the standard commodity, largely due to the impact of the beam support on the fire spread. Furthermore, the critical delivered flux (CDF) that can prevent fire growth is very close between the idealized and the standard commodity. The similarities in fire growth and suppression characteristics suggest that it may be feasible to use the idealized commodity in numerical simulation of fire suppression, as an alternative to the more complex real fuel.
\end{abstract}

KEYWORDS: suppression, commodity, flame spread, sprinkler, heat release rate

\section{NOMENCLATURE LISTING}

$\begin{array}{ll}A_{\text {duct }} & \text { cross sectional area }\left(\mathrm{m}^{2}\right) \\ c_{\text {flow }} & \text { flow coefficient } \\ c_{p} & \text { specific heat }(\mathrm{kJ} / \mathrm{kg} \cdot \mathrm{K}) \\ h & \text { heat transfer coefficient }\left(\mathrm{W} / \mathrm{m}^{2} \cdot \mathrm{K}\right) \\ \Delta h & \text { heat of combustion }(\mathrm{kJ} / \mathrm{kg}) \\ \dot{m} & \text { mass flow rate }(\mathrm{kJ} / \mathrm{kg}) \\ \dot{m}_{w}^{\prime \prime} & \text { water flux }(\mathrm{mm} / \mathrm{min}) \\ \Delta m & \text { collected water mass }(\mathrm{kJ} / \mathrm{kg}) \\ M w & \text { molecular weight }(\mathrm{kg} / \mathrm{mol}) \\ p & \text { absolute pressure }(\mathrm{Pa}) \\ \Delta p & \text { differential pressure }(\mathrm{Pa}) \\ \dot{q}^{\prime \prime} & \text { heat flux }\left(\mathrm{kW} / \mathrm{m}^{2}\right) \\ \dot{Q} & \text { heat release rate }(\mathrm{kW}) \\ R & \text { universal gas constant }(\mathrm{kJ} / \mathrm{kmol} \cdot \mathrm{K}) \\ R_{V T M} & \text { variation-to-mean ratio } \\ t & \text { time }(\mathrm{s}) \\ T & \text { temperature }(\mathrm{K})\end{array}$

$\begin{array}{ll}\text { Greek } & \\ \sigma & \text { Boltzmann constant } \\ \varepsilon & \text { emissivity } \\ \rho & \text { density }\left(\mathrm{kg} / \mathrm{m}^{3}\right) \\ \delta & \text { thickness }(\mathrm{mm}) \\ \text { Subscripts } \\ \infty & \text { far field } \\ \text { amb } & \text { ambient } \\ \text { be } & \text { beginning of extinguishment } \\ \text { conv } & \text { convective } \\ \text { chem } & \text { chemical } \\ \text { CO } & \text { carbon monoxide } \\ \text { CO2 } & \text { carbon dioxide } \\ \text { nofire } & \text { under no-fire conditions } \\ \text { O2 } & \text { oxygen } \\ \text { prod } & \text { combustion products } \\ \text { rad } & \text { radiation } \\ s & \text { surface }\end{array}$




\section{INTRODUCTION}

For fire safety and property protection, sprinkler systems have long been recognized as one of the most cost-effective and reliable technologies available. However, the physics associated with sprinkler protection are very complex, so that requirements and standards have mostly been developed by conducting largescale tests. These tests are usually expensive and the test results are difficult to generalize. In order to overcome the limitations of large-scale testing for sprinkler protection research, FM Global initiated collaborative efforts to develop predictive numerical models for large fires with sprinkler protection. As part of this modeling effort, FM Global also initiated a sprinkler technology program, aimed at guiding model development and providing validation data for fire protection using sprinklers. A more detailed description of the sprinkler technology program can be found in Ref. [1].

In the sprinkler technology program, experimental studies were designed and conducted with increasing levels of complexity, in order to understand the physics and validate the numerical models. In previous work [2], experimental techniques were explored to investigate key phenomena in sprinkler suppression, including water absorption by porous fuels, vertical and corner flows on fuel surfaces, water transport in rack storage, water evaporation subject to external radiation, and effects on burning rates in parallel panels subjected to pre-wetting. The results showed that most of the experimental techniques tested were appropriate for the intended studies, while some techniques, e.g., radiation-controlled single-wall burning test, needed improvement to obtain measurements suitable to guide model development and validate submodels. The experimental results also assisted the development of numerical models, and provided preliminary data to validate simulated results $[3,4,5]$. The comparisons of calculations and measurements in general showed qualitative and also, to some degree, quantitative agreement.

In addition to experimental studies of separate effects, model development and validation also require measurements from integrated processes as intermediate steps toward simulating large fires with sprinkler protection. These integrated processes mainly include interactions of the sprinkler spray and the fire plume as characterized by the actual delivered density measurements, and interactions of surface water flows and burning solid commodities, which are investigated in the present work.

The main objectives of this work are to better understand the physics associated with sprinkler suppression, and to provide model validation data for solid commodities under realistic, but simplified conditions. The realistic fire suppression conditions require that the selected experiment include fire growth, water application and extinguishment processes. Meanwhile, the selected fuel and the applied water flux should be relevant to sprinkler protection in engineering practice. The experimental conditions should also be simplified so that the key variables characterizing the fire development can be well controlled and measured with good repeatability.

The repeated tests bear further interest, in addition to providing validation data. In previous exploratory work [2], the water transport measurements in rack storage showed significant non-uniform water distributions on vertical fuel surfaces. When uniform water fluxes were applied on top of corrugated cardboard box commodities in rack storage, the water flows measured along the lateral width on the vertical fuel surfaces exhibited standard deviations of the same order of magnitude as the mean value. Such highly non-uniform water distribution on the fuel surfaces raises a number of questions. Is this phenomenon important to overall fire suppression? How can a numerical model account for this phenomenon if it is important? And if not, then what is the key quantity that needs to be simulated correctly so that overall suppression behavior can be captured? In order to answer these questions, there is a need to determine whether the non-uniform water distribution has a significant impact on the overall fire suppression for different water fluxes and heat release rates at the beginning of extinguishment. It is expected that the present work should provide model validation data, and also reveal the impact of the nonuniform water distribution on fire suppression. It should be noted that in the present work, the uniform water flux applied directly on top of the fuel array is a simplified condition compared to water fluxes delivered by sprinklers. In real sprinkler fires, the water fluxes reaching the top fuel surface are generally non-uniform because of sprinkler discharge pattern and penetration through the fire plume. Further discussions can be found in Ref. [6].

In order to achieve the aforementioned objectives, an experimental method was designed and discussed in detail in the next section. A series of water application tests were carried out using the designed experimental method. The subsequent section presents the experimental results, together with discussions 
and comparisons of measurements under various test conditions, especially the impact of applied water flux and the heat release rate (HRR) at the beginning of extinguishment. In addition, the measured fire growth rates and HRRs during suppression stages were also compared between the idealized and the standard commodities. Since the standard commodity is too complex to model, the comparison can help explore the feasibility of using the idealized commodity as an alternative to the real fuel. The last section summarizes the present work and discusses future work.

\section{EXPERIMENTAL METHOD}

Fire tests using the water application apparatus (WAA) were selected in this work to investigate the fire suppression behavior. In a WAA test, the fire is allowed to grow after ignition until a predetermined condition is achieved, e.g., a fixed HRR or a sprinkler activation temperature. Uniform water flux is then applied on top of the fuel array. The water flux is kept constant until the end of the test upon which the fire is either uncontrolled with the HRR increasing to the instrumentation limit, or controlled with the HRR decreasing significantly from its peak value and without further development. Based on a previous study [7], this type of test can help classify representative fuels for sprinkler protection purposes.

The WAA test includes all key processes of fire development in sprinkler fire protection, i.e., fire growth, water application and fire extinguishment. The fire development in the WAA test is characterized by the HRR during growth and suppression stages. This quantity can be measured using a calorimeter by collecting all combustion products. The HRRs obtained under different water fluxes can also be used to determine the critical delivered flux (CDF) of a given commodity [7], which is defined as the minimum water flux delivered on top of the fuel that can prevent fire growth. Results from previous work [7,8] suggest that the HRR can be measured reliably in WAA tests. The repeatability of the experimental results is crucial for model validation. In contrast, the HRR in full-scale sprinkler tests is not only difficult to measure, but also hard to reproduce, largely due to the interaction of the sprinkler activation sequence and fire development.

It should be noted that the selected experimental method is a simplified fire suppression test where a uniform water flux is applied over the entire fuel array. This method helps avoid the complications associated with the sprinkler activation sequence and the sprinkler spray and fire plume interaction. Both the sprinkler activation sequence and the spray/plume interaction are important in simulating sprinkler fire protection, and will be investigated through separate studies. Furthermore, the application of a uniform and steady-state water flux is also expected to help achieve reproducible test results, which will be evaluated in this work through repeated tests under identical experimental conditions.

\section{Fuel Array and Test Commodity}

All tests were carried out under the 20-MW calorimeter in the Large Burn Lab at the FM Global Research Campus, West Glocester, RI, USA. The test setup consisted of a fuel array in a rack storage configuration, the WAA and a set of water collectors for water transport measurements. The fuel array was a two-palletload wide, four-pallet-load long and three-tier high $(2 \times 4 \times 3)$ rack storage arrangement. The fuel used in the WAA test is a simplified commodity, referred to as idealized Class 2 (IC2) commodity in the present work. The IC2 commodity is simply the standard FM Global Class 2 commodity (three-layers of double-wall corrugated cardboard boxes with a metal liner inside, see Ref. 9), without the wood pallet. Since the fire spread on the corrugated cardboard can be affected by its moisture content, both the fuel and the laboratory were conditioned so that the moisture content (dry-basis) of the fuel was controlled between $6 \pm 2 \%$ before ignition in all the fire tests.

Fig. 1 shows the schematic of the test setup in elevation and plan views. Each pallet load of the IC2 commodity had a nominal dimension of $1.07 \mathrm{~m} \times 1.07 \mathrm{~m} \times 1.07 \mathrm{~m}$. The flue space was $0.15 \mathrm{~m}$ in both the longitudinal and transversal directions. The vertical tier-to-tier gap was $0.46 \mathrm{~m}$, measured from the top surface of a lower tier to the bottom surface of an upper tier. The overall test setup measured $4.72 \mathrm{~m}$ in length, $2.29 \mathrm{~m}$ in width and $4.24 \mathrm{~m}$ in height. On average, each pallet load of IC2 commodity contained $34.9 \mathrm{~kg}$ of combustible materials. The total combustible materials of the entire fuel array weighed $836.8 \mathrm{~kg}$.

Each pallet load of the IC2 commodity was supported by two steel beams at the bottom surface, since wood pallets were not used in the fuel array. Each steel beam was $0.13-\mathrm{m}$ high and $0.91-\mathrm{m}$ long in the transversal direction. The nominal separation distance between the two supporting beams was $0.81 \mathrm{~m}$ in the longitudinal direction. By the use of beam supports, the entire bottom surface area of the corrugated box 
can be exposed to the fire, while the fire propagation in the lateral direction may be affected by the beam height $(0.13 \mathrm{~m})$. This idealized commodity was designed to make the fuel geometry and material properties amenable to numerical simulations. The overall impact on fire growth and suppression of using the beam support will be evaluated in the section of Results and Discussions.

Uniform water fluxes were applied to the fuel array using the WAA. The water applicator delivered uniform water fluxes through six parallel steel pipes with $0.61-\mathrm{m}$ separation distance. On each pipe, eight nozzles (Spray System Co.) were installed in $0.61-\mathrm{m}$ intervals. The pipes were positioned above the fuel array so that the distance between the top surface of the fuel array and the nozzle exit was $0.2 \mathrm{~m}$. This setup created a coverage area of $0.61 \mathrm{~m} \times 0.61 \mathrm{~m}$ for each nozzle that generates a $120^{\circ}$ full-cone spray. Calibrations using collection pans $(0.3 \mathrm{~m} \times 0.3 \mathrm{~m})$ showed that the water flux distributions from the nozzles were within $\pm 5 \%$ under steady state conditions in previous work [7]. The water supply to the water applicator was controlled by a system of valves, pressure regulators and air relievers. More details of the WAA can be found in Ref. [7].
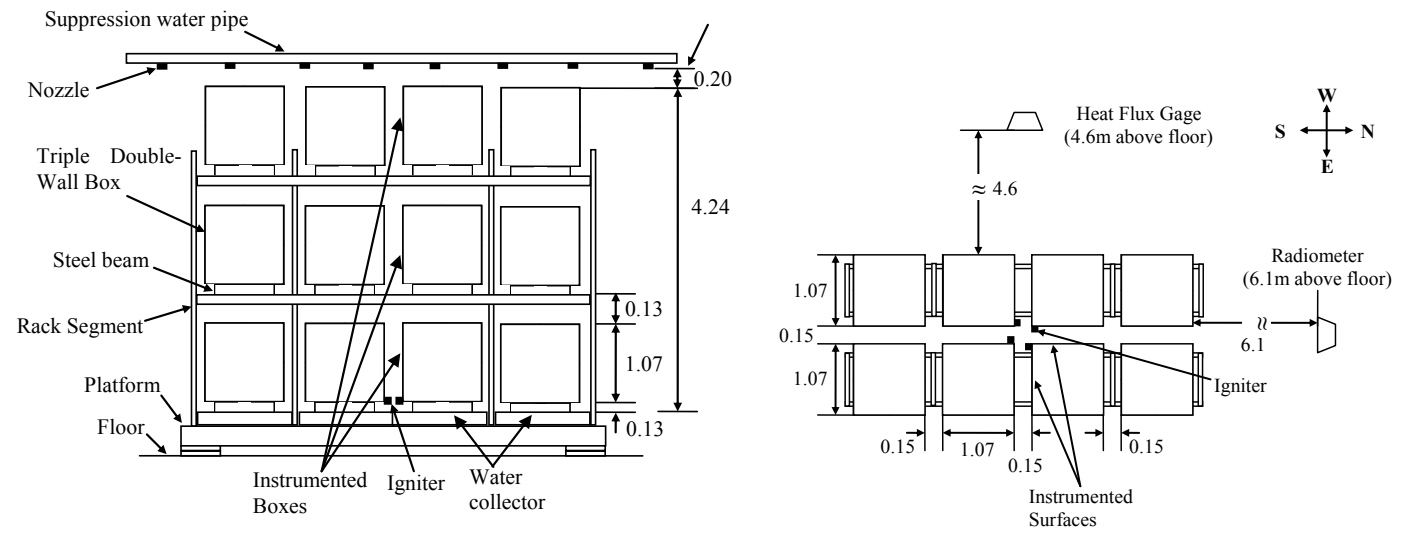

Fig. 1. Elevation and plan view of the water application test setup.

\section{Instrumentation and Measurements}

The instrumentation used in this work includes all calorimeter probes (pressure, temperature and gas concentration), a heat flux gage and a radiometer, a set of water collectors placed beneath the fuel array and thermocouples and plate thermometers installed on selected fuel surfaces (see Fig. 1). These instruments were intended to quantify the fire development in terms of global variables such as the HRR and the flow rate of water transport, and in terms of local variables such as the incident heat flux to and the temperature on the fuel surface.

The calorimeter probes provide measurements of exhaust flow in terms of temperatures, pressures and combustion product concentrations. The HRR can be calculated based on either oxygen consumption or $\mathrm{CO}_{2}-\mathrm{CO}$ generation method,

$$
\begin{aligned}
& \dot{Q}_{\text {chem }, \mathrm{O} 2}=\dot{m}_{\text {prod }}\left(M w_{\mathrm{O} 2} / M w_{\text {prod }}\right) \Delta h_{\mathrm{O} 2}\left(x_{\mathrm{O} 2, \infty}-x_{\mathrm{O} 2}\right), \\
& \dot{Q}_{\text {chem }, \mathrm{CO} 2 \mathrm{CO}}=\dot{m}_{\text {prod }}\left[M w_{\mathrm{CO} 2} \Delta h_{\mathrm{CO} 2}\left(x_{\mathrm{CO} 2}-x_{\mathrm{CO} 2, \infty}\right)+M w_{C O} \Delta h_{\mathrm{CO}}\left(x_{C O}-x_{C O, \infty}\right)\right] / M w_{\text {prod }},
\end{aligned}
$$

where $\dot{Q}_{\text {chem }, O 2}$ and $\dot{Q}_{\text {chem, } C O 2 C O}$ are chemical HRRs based on the two equations above; $M w_{\mathrm{O} 2}, M_{\mathrm{CO}_{2}}$, $M w_{C O}$ and $M w_{\text {prod }}$ are the molecular weights of $\mathrm{O}_{2}, \mathrm{CO}_{2}, \mathrm{CO}$ and combustion products, respectively. In this work, the molecular weight of the combustion products was approximated as that of the air. The heat of combustions associated with oxygen consumption and $\mathrm{CO}_{2}$ and $\mathrm{CO}$ generation are $\Delta h_{\mathrm{O} 2}=12.8 \mathrm{~kJ} / \mathrm{g}, \Delta h_{\mathrm{CO} 2}$ $=9.5 \mathrm{~kJ} / \mathrm{g}$ and $\Delta h_{C O}=5.0 \mathrm{~kJ} / \mathrm{g}$, respectively; $x_{\mathrm{O} 2}, x_{\mathrm{CO} 2}$ and $x_{C O}$ are measured volumetric fractions of each 
gas species. In order to avoid the impact of water, all gas analysis in this work were conducted based on dry samples. In Eqs. 1 and 2, the mass flow rate of combustion products, $\dot{m}_{\text {prod }}$, was determined from

$$
\dot{m}_{\text {prod }}=\left(p_{\text {prod }} M w_{\text {prod }} / R T_{\text {prod }}\right) C_{\text {flow }} \sqrt{\Delta p_{\text {prod }} A_{\text {duct }}} \text {, }
$$

where $p_{\text {prod }}, \Delta p_{\text {prod }}$ and $T_{\text {prod }}$ are the absolute and differential pressure and temperature of combustion products measured in the calorimeter duct; $R=8.314 \mathrm{~kJ} / \mathrm{kmol} \cdot \mathrm{K}$ is the universal gas constant, and $C_{\text {flow }}=$ 0.96 and $A_{\text {duct }}=7.30 \mathrm{~m}^{2}$ are flow coefficient and cross-sectional area of the calorimeter duct, respectively. After each test, the HRRs were calculated using the two aforementioned methods and were compared to ensure their consistency. The HRR values reported in the next section are based on the $\mathrm{CO}_{2}-\mathrm{CO}$ generation method due to its better accuracy.

Throughout the test series, the exhaust flow rate of the 20-MW calorimeter was maintained nominally at $135 \mathrm{~kg} / \mathrm{s}$ under ambient conditions of $20^{\circ} \mathrm{C}$ and $1 \mathrm{~atm}$. Given this exhaust flow rate, the pressure and temperature measurements at the calorimeter station were delayed by about 9 seconds compared to the fire source. This delay time includes the transport time of combustion products from the fire to the calorimeter inlet and the transport time from the calorimeter inlet to the instrumentation station. The gas concentrations including $\mathrm{O}_{2}, \mathrm{CO}_{2}$, CO were further delayed by approximately 25 seconds due to transport from the instrumentation station to the gas analyzers. Since the mass flow in the calorimeter duct was maintained largely constant, the HRR values were only adjusted by 34 seconds in post-processing to account for the time delays. It should be pointed out that the delay times caused by the transport of the combustion products into the duct flow are sensitive to the fire size. In general, the delay times tend to be shorter in the freeburn stage when the fire size is large compared to when the fire size is small or when the fire is significantly suppressed. During suppression, the cooling power of the water is so strong that the combustion products are often driven down to the floor level migrating horizontally, before eventually entering into the calorimeter.

Water collectors were used in this work to quantify the amount of water that could reach the bottom of the fuel array. As shown in Fig. 1, the water collectors were positioned below the bottom tier of the fuel array. Eight water collectors were placed directly below a fuel stack. The center collectors located below the four fuel stacks in the middle of the fuel array were $1.22 \mathrm{~m} \times 1.21 \mathrm{~m}$ and $0.3-\mathrm{m}$ tall, while the other four end collectors were $1.22 \mathrm{~m} \times 1.17 \mathrm{~m}$ and $0.3-\mathrm{m}$ tall due to limited space to fit them into the racks. All water collectors were joined together, with the small gaps between adjacent collectors being covered by steel angles. This design was aimed at collecting all water delivered to the bottom of the commodities as well as the water in the flue spaces. The top surfaces of the water collectors were covered by a metal mesh to prevent large debris from falling into the collector and distorting the measurements. A pressure transducer was connected to the bottom drain of each collector through stainless steel tubes. The pressure signals were calibrated to measure transient water mass collected below each fuel stack. This set of water collection data is expected to help characterize water transport through burning commodities in a rack storage configuration.

To further assist characterization of fire growth, three corrugated boxes (see Fig. 1) were instrumented with thermocouples (TC) and plate thermometers (PT) [10] installed flush with the fuel surface. For each instrumented corrugated cardboard box, one plate thermometer was installed at the surface center, and four thermocouples were installed $25 \mathrm{~cm}$ above, below, and to each lateral side of the plate thermometer.

The TCs were K-type, 0.8-mm diameter butt-welded unsheathed thermocouples (Omega CHAL-032-BW). Each PT was custom-built by attaching a K-type 0.25 - $\mathrm{mm}$ diameter thermocouple onto the back of a 2.54 $\mathrm{cm}$ square stainless steel plate of $0.46 \mathrm{~mm}$ thickness using a high-temperature metal adhesive. Details of these probes have been given by Chaos and Khan [10]. Based on Ref. [10], the heat flux to the fuel surface can be estimated as

$$
\dot{q}_{\text {rad }}^{\prime \prime}=\left[\rho c_{p} \delta(d T / d t)+\sigma \delta T_{s}^{4}+h_{\text {conv }}\left(T_{s}-T_{a m b}\right)+h_{\text {loss }}\left(T_{s}-T_{\text {loss }}\right)\right] / \varepsilon+\dot{q}_{\text {offset }}^{\prime \prime}
$$


where $\dot{q}_{\text {offset }}^{\prime \prime}=\left[h_{\text {conv }}\left(T_{\infty}-T_{s}\right)+h_{\text {loss }}\left(T_{\infty}-T_{\text {loss }}\right)-\varepsilon \delta T_{\infty}^{4}\right] / \varepsilon$. In Eq. $4, \dot{q}_{\text {rad }}^{\prime \prime}$ is the incident heat flux to the fuel surface, including both radiation and convection components; $\rho, c_{p}$ and $\delta$ are the density, specific heat and thickness of the PT, respectively; $\varepsilon$ is the surface emissivity; $T_{s}$ is the PT surface temperature measured by the aforementioned TC; $\sigma=5.67 \times 10^{-8} \mathrm{~W} / \mathrm{m}^{2} \cdot \mathrm{K}^{4}$ is the Stephan-Boltzmann constant; $h_{\text {conv }}$ and $h_{\text {loss }}$ are heat transfer coefficients for convection on the front surface and heat loss to the back surface of the steel plate, respectively; $T_{\infty}$ is the room temperature in the lab measured far away from the test site; $T_{a m b}$ is the ambient temperature in the vicinity of PT front surface; and is the temperature for heat loss to the PT back surface.

Equation 4 is developed based on transient energy balance on a control volume around the thin metal plate. The terms in the square bracket on the right-hand-side of Eq. 4 include transient heat storage, surface reradiation, convection loss on the front and back surfaces of the PT. In this work, $\rho=7800 \mathrm{~kg} / \mathrm{m}^{3}, c_{p}=509$ $\mathrm{J} / \mathrm{kg} \cdot \mathrm{K}$ and $\delta=0.46 \mathrm{~mm}$ were taken as the properties of the stainless steel plate; $\varepsilon$ is 0.96 because highemissivity paint was applied on the PT front surface; the ambient temperature $T_{a m b}=1400 \mathrm{~K}$, the back surface temperature $T_{\text {loss }}=450 \mathrm{~K}$, and the heat transfer coefficients $h_{\text {conv }}=15 \mathrm{~W} / \mathrm{m}^{2} \cdot \mathrm{K}$ and $h_{\text {loss }}$ $=35 \mathrm{~W} / \mathrm{m}^{2} \cdot \mathrm{K}$ were adopted from Ref. [10]. Note that the values of $T_{a m b}$ and $T_{\text {loss }}$ were determined to best match heat flux gage data during calibration under fixed external heat fluxes. The use of these values in the energy balance creates a non-physical initial value $\left(t=0, T_{s}=T_{\infty}\right.$ and $\left.d T_{s} / d t=0\right)$ for the heat flux $\dot{q}_{\text {rad }}^{\prime \prime}$. Therefore, an offset value, $\dot{q}_{\text {offset }}^{\prime \prime}$, is included in Eq. 4 for compensation. The TCs and PTs are expected to provide detailed information of flame propagation and heat transfer to the fuel surface during the freeburn stage of the fire test. Once water is applied to the fuel array, the measurements from the TCs and PTs can become very difficult to interpret. Consequently, the TC and PT data collected during the suppression stage of the WAA tests were not considered as quantitative measurements.

\section{Test Matrix}

Table 1 lists the matrix of WAA tests reported in this work. All tests were conducted using the $2 \times 4 \times 3$ fuel array with the beam support. The water flux and the convective HRR at the beginning of extinguishment ( $\dot{Q}_{b e, \text { conv }}$ ) were changed to observe their impact on the fire suppression behavior. Note that the quantity $\dot{Q}_{b e, c o n v}$ was used to control the water application, which was monitored after ignition during the test. Once the values of $\dot{Q}_{b e, \text { conv }}$, given in Table 1, were reached, the predetermined uniform water flux was applied on top of the entire fuel array. Due to transport delay of combustion products ( 9 seconds), the actual convective HRRs in the tests are all greater than the values listed in Table 1. The specific chemical HRR at the beginning of extinguishment, $\dot{Q}_{b e, c h e m}$, in each WAA test will be given in the next section. In addition, a number of water collection tests under no-fire conditions were also included to characterize the baseline water transport in the rack storage using beam support.

Table 1. Test matrix of WAA Tests

\begin{tabular}{c|c|c|c|c}
\hline Test No. & Fuel & Test array & $\dot{m}_{w}^{\prime \prime}(\mathrm{mm} / \mathrm{min})$ & Water Application Condition \\
\hline $1-2$ & Idealized Class 2 & $2 \times 4,3$ & 12 & $\dot{Q}_{b e, c o n v}=3.5 \mathrm{MW}$ \\
$3-5$ & Idealized Class 2 & $2 \times 4,3$ & 8 & $\dot{Q}_{b e, c o n v}=3.5 \mathrm{MW}$ \\
$6-7$ & Idealized Class 2 & $2 \times 4,3$ & 4 & $\dot{Q}_{b e, c o n v}=3.5 \mathrm{MW}$ \\
8 & Idealized Class 2 & $2 \times 4,3$ & 4 & $\dot{Q}_{b e, c o n v}=5.0 \mathrm{MW}$ \\
9 & Idealized Class 2 & $2 \times 4,3$ & 8 & $\dot{Q}_{b e, c o n v}=5.0 \mathrm{MW}$ \\
10 & Idealized Class 2 & $2 \times 4,3$ & 12 & $\dot{Q}_{b e, c o n v}=5.0 \mathrm{MW}$ \\
\hline
\end{tabular}




\section{RESULTS AND DISCUSSIONS}

\section{Test Repeatability}

The test repeatability is shown in Fig. 2 through comparison of HRR data acquired under identical experimental conditions. The controlled experimental conditions include the ambient and initial lab environment, the fuel array setup and instrumentations, the HRR upon water application and the applied water flux. Since each test condition was only repeated once in this work, a simple measure of test repeatability, $R_{V T M}$, is defined as the variation-to-mean ratio for a quantity of interest,

$$
R_{V T M}=\frac{\left|q_{\max }-q_{\min }\right| / 2}{\sum_{i=1}^{N} q_{i} / N}
$$

In Eq. 5, $q_{\max }$ and $q_{\min }$ are the maximum and minimum values of any quantity $q$ of interest, respectively, such as HRR and total integrated chemical energy; the denominator is the averaged value of all tests conducted. Note that this simple definition of test repeatability only applies to a test series of limited repeating cases, e.g., $2<N<4$. Table 2 lists the variation-to-mean ratios, $R_{V T M}$, for the tests with $\dot{Q}_{b e, c h e m}=$ 6.4 MW and using water fluxes of $4 \mathrm{~mm} / \mathrm{min}$ (Test 6 and 7), $8 \mathrm{~mm} / \mathrm{min}$ (Test 3 and 5) and $12 \mathrm{~mm} / \mathrm{min}$ (Test 1 and 2). Note that the chemical HRR at the beginning of extinguishment, $\dot{Q}_{b e, c h e m}=6.4 \mathrm{MW}$, is obtained by averaging the corresponding values of all tests conducted using $\dot{Q}_{b e, c o n v}=3.5 \mathrm{MW}$.
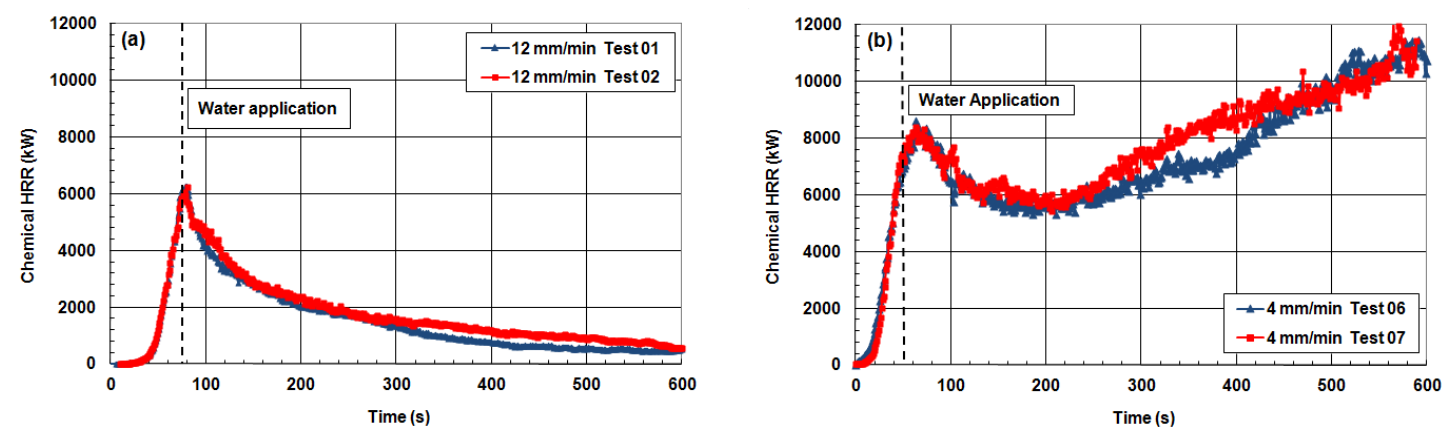

Fig. 2. HRRs of repeated tests under the same water flux ( $\left.\dot{Q}_{b e, c h e m}=6.4 \mathrm{MW}\right)$.

The $R_{V T M}$ for chemical energy during fire growth was calculated using HRR data 50 seconds prior to water application $\left(t=t_{b e}\right.$ ), while the calculation of $R_{V T M}$ during suppression used data 500 seconds after water application. The data used for calculating the total $R_{V T M}$ value is 600 seconds after ignition. In addition to the $R_{V T M}$ associated with the chemical energy, variations about HRR were also examined in terms of maximum fire size and HRR at the beginning of extinguishment. As shown in Table 2, all these variationto-mean ratios are less than $8 \%$, indicating high repeatability of the test results. Although the experimental conditions of Tests 8-10 were not repeated in this work, the repeatability of these tests is expected to be similar to those for Tests 1-3 and 5-7.

Given the scale of these WAA tests, the repeatability is deemed satisfactory in the present work. Therefore, the experimental results are suitable for model validation purposes. Furthermore, the high repeatability also suggests that the randomness associated with test conditions does not cause significant variations in the overall suppression behavior as measured by the HRRs. Therefore, quantities other than the local water flow distributions on the fuel surface should be controlling the fire suppression performance. 
Table 2. Test repeatability $\left(R_{V T M}\right)$ using beam-supported arrays with $\dot{Q}_{b e, c h e m}=6.4 \mathrm{MW}$.

\begin{tabular}{|c|c|c|c|c|c|}
\hline \multirow{2}{*}{$\begin{array}{c}\text { Flux } \\
(\mathrm{mm} / \mathrm{min})\end{array}$} & \multicolumn{3}{|c|}{$R_{V T M}$ of Chemical Energy $\Delta E$} & \multicolumn{2}{|c|}{$R_{V T M}$ of $\operatorname{HRR}(\dot{Q})$} \\
\hline & $\begin{array}{c}\text { Fire growth } \\
t=\left(t_{b e}-50 s, t_{b e}\right)\end{array}$ & $\begin{array}{c}\text { Suppression } \\
t=\left(t_{b e}, t_{b e}+500 s\right)\end{array}$ & $\begin{array}{c}\text { Total } \\
t=(0,600 s)\end{array}$ & $t=\dot{Q}_{\max }$ & $\begin{array}{c}\dot{Q}_{b e, \text { chem }} \\
t=t_{b e}\end{array}$ \\
\hline 4 & $1.6 \%$ & $2.8 \%$ & $0.8 \%$ & $1.4 \%$ & $3.4 \%$ \\
\hline 8 & $3.0 \%$ & $6.7 \%$ & $6.3 \%$ & $3.8 \%$ & $1.2 \%$ \\
\hline 12 & $2.2 \%$ & $7.6 \%$ & $7.2 \%$ & $0.4 \%$ & $3.7 \%$ \\
\hline
\end{tabular}

\section{Effects of water flux on HRR}

The effects on fire suppression of applying different water fluxes are shown in Fig. 3 in terms of chemical HRRs. The averaged chemical HRRs at the beginning of extinguishment are 6.4 MW and 8.5 MW respectively in the two figures, which correspond to convective HRRs of 3.5 MW and 5.0 MW for water application. The freeburn data were taken from the work of Chaos [11] using the same fuel array setup. From Fig. 3, the heat release rates in all water application tests decreased shortly after water application. In the cases with relatively low water flux, i.e., $4 \mathrm{~mm} / \mathrm{min}$, the heat release rates of the fires began to increase around $250 \mathrm{~s}$ after ignition. In contrast, the heat release rates of the fires continued decreasing under higher water fluxes of 8 and $12 \mathrm{~mm} / \mathrm{min}$. These suppression behaviors are qualitatively identical to observations in previous commodity classification studies [7]. Following the CDF definition in Ref. [7], the CDF values for $\dot{Q}_{b e, c h e m}=6.4 \mathrm{MW}$ are $4.48 \mathrm{~mm} / \mathrm{min}$ using Test 1,3 and 6 , and $4.31 \mathrm{~mm} / \mathrm{min}$ using Test 2,5 and 7 , with a variation of $1.9 \%$ around the mean value of $4.40 \mathrm{~mm} / \mathrm{min}$. As for $\dot{Q}_{b e, c h e m}=8.5 \mathrm{MW}$, the calculated CDF is $4.44 \mathrm{~mm} / \mathrm{min}$ using Test 8,9 and 10 . These CDF values are very close to those of standard Class 2 commodity $(4.88 \mathrm{~mm} / \mathrm{min})$, reported in Ref. [7], indicating that these two fuels have similar behaviors in response to water application under the tested conditions.
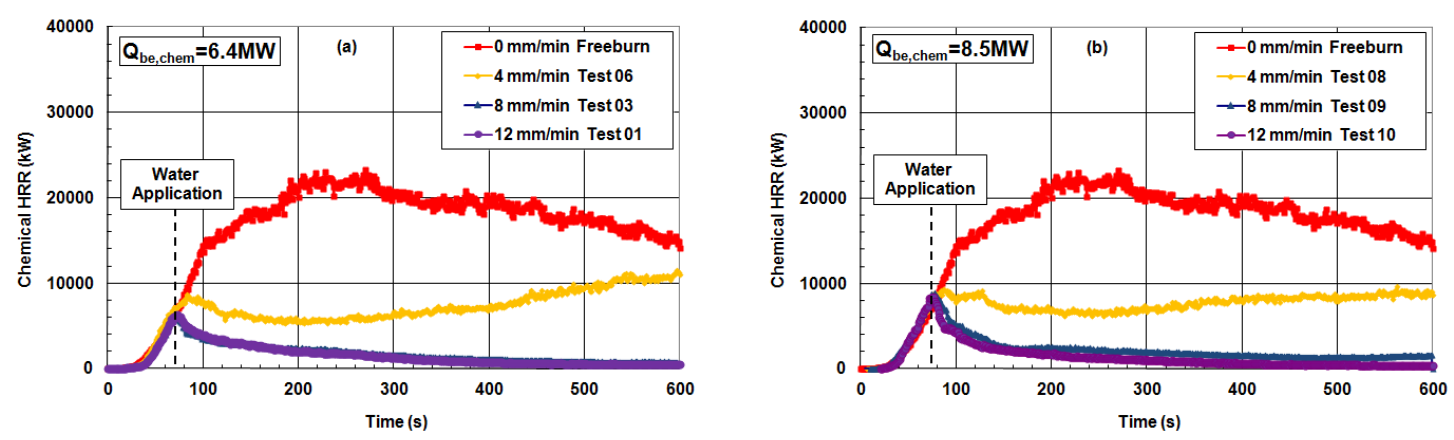

Fig. 3. Effects of water flux on chemical HRRs.

According to recent studies on suppression physics [2], with increasing water fluxes applied on the fuel array, the water flows generated on fuel surfaces tend to be more like continuous films than discrete rivulets, the water films tend to be thicker in the direction normal to the fuel surface and flow faster in the vertical direction, and less water tends to be evaporated by the same amount of flame radiation. When the applied water flux is sufficient to overcome evaporation due to flame heat transfer, surface cooling on unburned commodities prevents further fire propagation beyond the burning zones at the time of water application. This effect, combined with cooling of the burning fuel surface as well as fuel burnout, results in decreasing heat release rates as shown in Fig. 3. Therefore, these data provide strong validation to assess numerical models, when the dominant suppression mechanism is the cooling of fuel surfaces by water flows. 


\section{Effects of HRR at the beginning of extinguishment}

Figure 4 shows the effects of HRR at the beginning of extinguishment, $\dot{Q}_{b e, c h e m}$, on fire suppression under two water fluxes: 4 and $12 \mathrm{~mm} / \mathrm{min}$. Note that, in Tests 8-10, the water application was controlled using $\dot{Q}_{b e, c o n v}=5 \mathrm{MW}$. Due to transport delay of combustion products, the actual averaged chemical and convective HRRs upon water application were $8.5 \mathrm{MW}$ and 5.6 MW, respectively. When the HRR at the beginning of extinguishment is higher, the heat release rate also tends to be higher shortly after water application $(80 \sim 100 \mathrm{~s})$. However, there appears to be a steeper decrease in the HRR with increasing $\dot{Q}_{b e, c h e m}$ values, especially when the water fluxes are sufficient to suppress the fire, e.g., $12 \mathrm{~mm} / \mathrm{min}$. After the steep decrease of HRR in the suppressed fires, the difference in HRR between the higher and lower $\dot{Q}_{b e, c h e m}$ cases are no longer significant. In the cases when the fire is not controlled, the higher $\dot{Q}_{b e, c h e m}$ test experienced crossover of its HRR with the lower $\dot{Q}_{b e, c h e m}$ test (Fig. 4). As a result, the accumulated energy release does not exhibit significant differences for each pair of tests with different $\dot{Q}_{b e, c h e m}$, but the same water flux. The results of applying $8 \mathrm{~mm} / \mathrm{min}$ water flux are qualitatively similar to those of $12 \mathrm{~mm} / \mathrm{min}$ and thus are not included in this paper. Comparisons of Figs. 3 and 4 suggest that the variation of water flux around the critical value plays a more important role than that of HRR at the beginning of extinguishment. This is also confirmed by the negligible change $(<1 \%)$ in CDF values when the average $\dot{Q}_{b e, \text { chem }}$ increased from 6.4 MW to $8.5 \mathrm{MW}$, as discussed in the previous section.
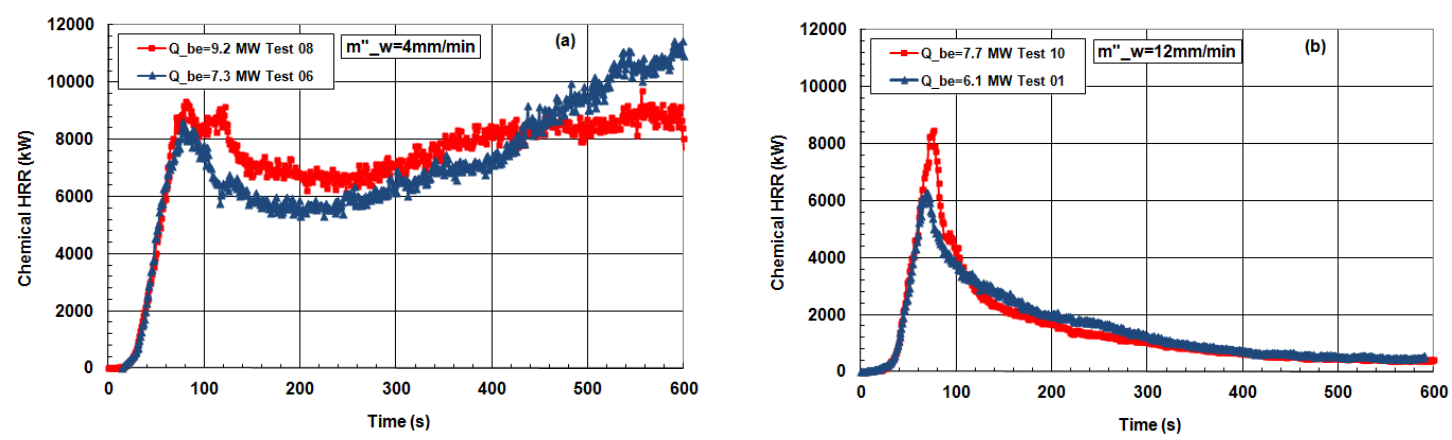

Fig. 4. Effects of $\dot{Q}_{b e, c h e m}$ on chemical HRRs.

\section{Incident heat flux to and temperatures on fuel surfaces}

Measurements of PTs and TCs are plotted in Fig. 5 using data from Test 6 as examples to show incident heat fluxes to and temperatures on fuel surfaces. In each panel of Fig. 5, either two PT or four TC measurements are plotted on the same tier level with a vertical dash line indicating the water application time. In Test 6 , the fire was uncontrolled with flames propagating laterally to the end of the $2 \times 4 \times 3$ fuel array (see Fig. 2 for the HRR).

The PT and TC measurements were conducted in a very challenging environment, under both flame heat transfer and surface water flows. Since the PT and TC were originally designed and calibrated to measure heat flux and surface temperature under dry-fuel conditions, ${ }^{10}$ the experimental data can hardly be trusted when the PT and TC surfaces become wet. Therefore, during the freeburn stage of the WAA tests, the PT and TC data can be used to assess the incident flame heat flux and the surface temperature; while during the suppression stage of the test, judgment has to be exercised carefully regarding the use of these measurements. In addition, charred and peeled cardboard may block the PT front surface and the TC bead, resulting in signals that do not represent the intended measurements. Furthermore, as the corrugated cardboard burns out, front surfaces of the PTs and the TC beads are no longer flush with the fuel surface. Consequently, the measurements do not represent the incident heat fluxes to or temperatures on the fuel surface. Since the thermocouple lines from the PT need to be bent and guided through the fuel boxes, some welding points to the steel plate became loose or broken, leading to no signal for the PT channel. This is reflected as a horizontal line in some plots. The interpretation of the experimental results can be further 
complicated since the PT and TC signals are essentially point measurements, while the flame zone can move around the vertical axis of the fuel array laterally during both fire growth and suppression stages. Based on these assessments, only first $200 \mathrm{~s}$ of data were shown in Fig. 5 since the rest were unreliable.

Given all the complexities associated with the heat flux and surface temperature measurements, the experimental results still reveal the controlling factors in fire growth and, to some degree, in fire suppression. In general, the incident heat flux increases with time before water application, which is consistent with the HRR growth. This suggests that the fire growth is driven by flame heat transfer. From Fig. 5, it appears that the change of incident heat flux with time has two stages: a slow start peaking at $10 \sim$ $20 \mathrm{~kW} / \mathrm{m}^{2}$, and a subsequent sharp jump to $\sim 150 \mathrm{~kW} / \mathrm{m}^{2}$. The first stage may be associated with preheating of the fuel, while the second stage could be the result of flames burning immediately in the vicinity of the fuel surface where the PT was installed. Given the heat flux magnitudes in these two stages, it is likely that convective and radiative heat transfer play more important role in preheating and burning processes, respectively. The TC measurements show that generally the surface temperatures increase with time as the fuel surface is being preheated, and then rise sharply to approximately $700^{\circ} \mathrm{C}$ which is close to pyrolysis temperature on the fuel surface under similar heat flux reported by Chaos et al.[12]. The variations among the four TCs, especially the two at laterally symmetrical locations, also revealed that the flames might be tilted slightly toward one direction in the experiments.
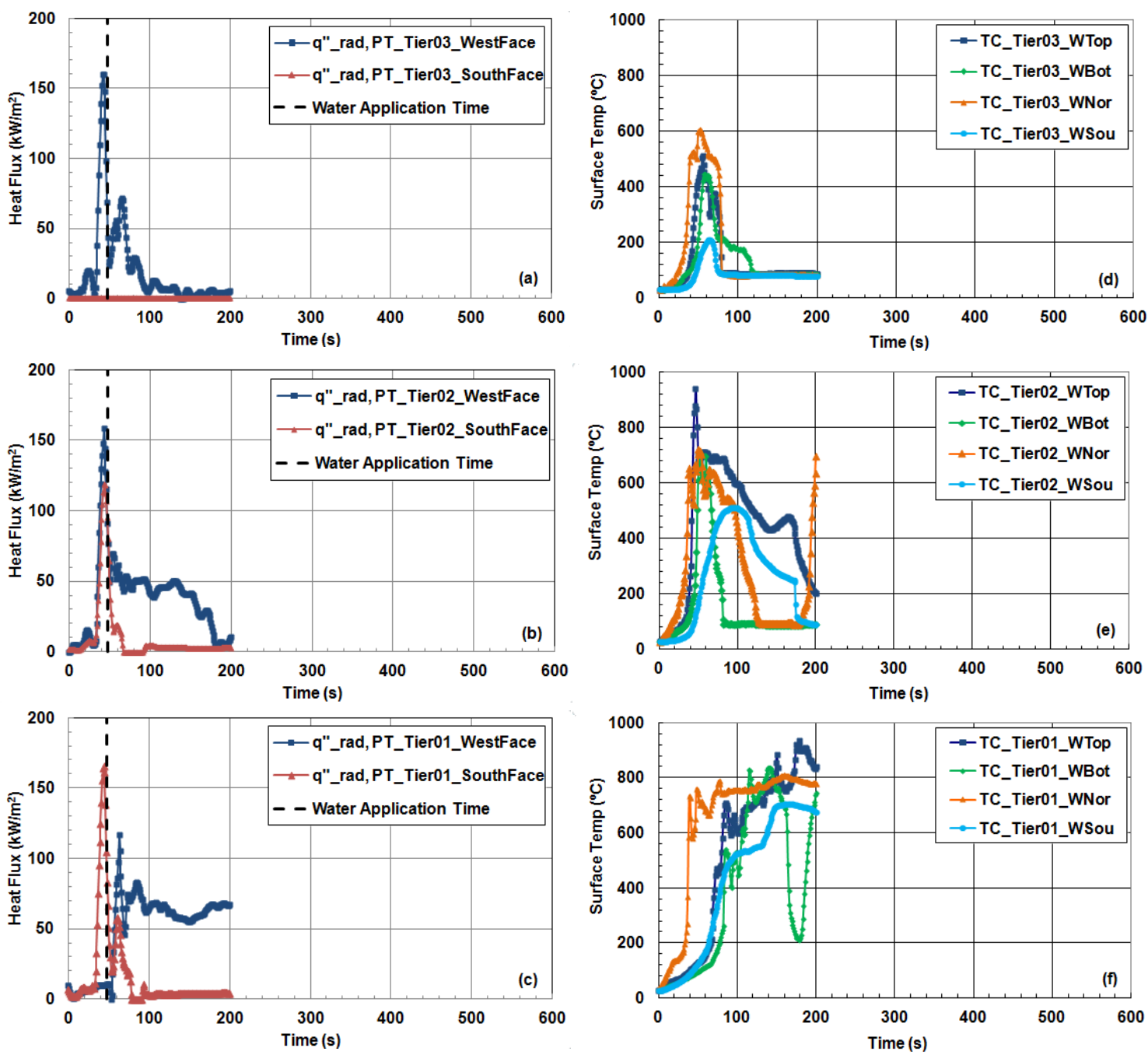

Fig. 5. Heat fluxes and temperatures on fuel surfaces in Test 6 ( $\left.Q_{c o n v, b e}=3.5 \mathrm{MW}, \dot{m}_{w}^{\prime \prime}=4 \mathrm{~mm} / \mathrm{min}\right)$. 


\section{Water transport in WAA tests}

The results of water collection tests are presented in Fig. 6 for both controlled $\left(\dot{m}_{w}^{\prime \prime}=12 \mathrm{~mm} / \mathrm{min}\right)$ and uncontrolled ( $\dot{m}_{w}^{\prime \prime}=4 \mathrm{~mm} / \mathrm{min}$ ) fires. As described earlier, eight water collection pans were placed below the $2 \times 4 \times 3$ fuel array, four beneath the center stacks and four beneath the stacks at the north and south end. Due to excessive heat to the tubes connecting the pressure transducers, some test data exhibited nonphysical signals that were excluded. Figure 6 also included repeated tests under the same conditions of water application and applied water flux with the upper and lower panels representing collections under the center and the end fuel stacks, respectively. The accumulated water as a function of time, $\Delta m(t)$, measured in WAA tests was normalized by their counterparts under no fire conditions, $\Delta m_{n o f i r e}$, at $t=t_{b e}+500 s$, i.e., 500 seconds after water application. Note that the initial time in Fig. 6 represents $t=t_{b e}$, which is different from all HRR plots shown elsewhere in this work.
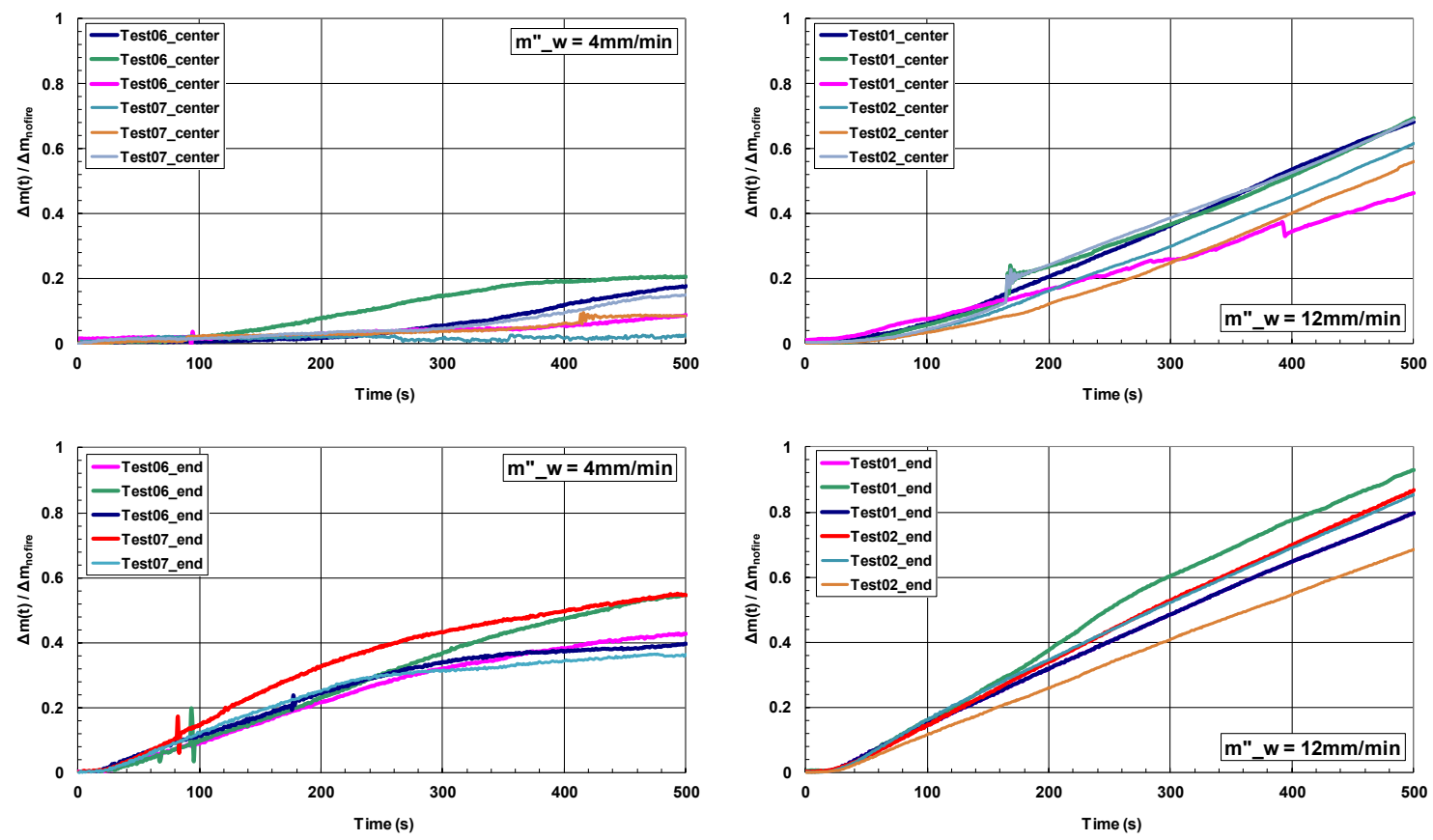

Fig. 6. Normalized water collection under uniform water fluxes.

It can be seen from Fig. 6 that the fraction of water transported to the bottom of the center fuel stacks is less than that of the end stacks under all fire scenarios. In addition, more water is transported to the bottom of the fuel stacks when the fire is controlled than when the fire is uncontrolled. At $t=t_{b e}+500 \mathrm{~s}$, the amount of water transported to the bottom of the fuel array is $\sim 20 \%$ or less below the center stacks, compared to $40 \sim 60 \%$ below the end stacks, when the fire is uncontrolled. If the fire is controlled, both ratios increase significantly, to $45 \sim 65 \%$ under the center stacks and to $70 \sim 90 \%$ under the end stacks. Note that these changes in percentages have accounted for the differences in applied water fluxes through normalization using the amount of water collected under no fire conditions. Therefore, water transport is affected significantly depending on the suppression outcome and the relative location to the burning zone.

The lost water in WAA tests can be attributed to a number of reasons: water evaporation due to flame heat transfer; separation of water flows due to splashing and surface charring and peeling; change of water spray patterns discharged from the nozzles due to fire plumes; and water absorption by the corrugated cardboard. Given the significant differences in the normalized water mass fraction and the fire size for controlled and uncontrolled fires, the results in Fig. 6 suggest that water evaporation due to fame heat transfer might be the dominant mechanism controlling the water transport. 


\section{Comparison with the standard Class 2 commodity}

As mentioned earlier, the idealized Class 2 commodity was designed based on the standard Class 2 commodity, in order to make it amenable to numerical modeling while keeping its fire growth and suppression behaviors similar to the real fuel. To examine the difference proximity between the idealized and the standard commodity, Figures 7 and 8 compare the fire development of the two commodities before and after water applications. Note that in Fig. 7, all HRR curves were shifted in time and clustered around $2 \mathrm{MW}$, in order to eliminate the uncertainties associated with the ignition process and the very early fire growth, which were deemed to have relatively minor impact on water application. The data for the standard Class 2 commodity were taken from the work described in Ref. 7.

Prior to the water application, the fires grow from $2.5 \mathrm{MW}$ to $7.5 \mathrm{MW}$ in approximately 40 seconds for the standard Class 2 (see Fig. 7); in contrast, the IC2 fire size can increase in the same HRR range in about 30 seconds. It should also be pointed out that the fire growth rates before water application are associated with approximately $15 \%$ uncertainties for both fuels. Given all these results, the simplified Class 2 commodity appears to be growing faster than the standard Class 2 commodity by $\sim 33 \%$. Moisture content measured approximately 15-20 minutes before ignition in all the tests was also examined. As discussed earlier, this quantity was controlled at $6 \pm 2 \%$ based on dry fuel. Examination of the moisture content against the fire growth rate didn't yield any consistent trend.
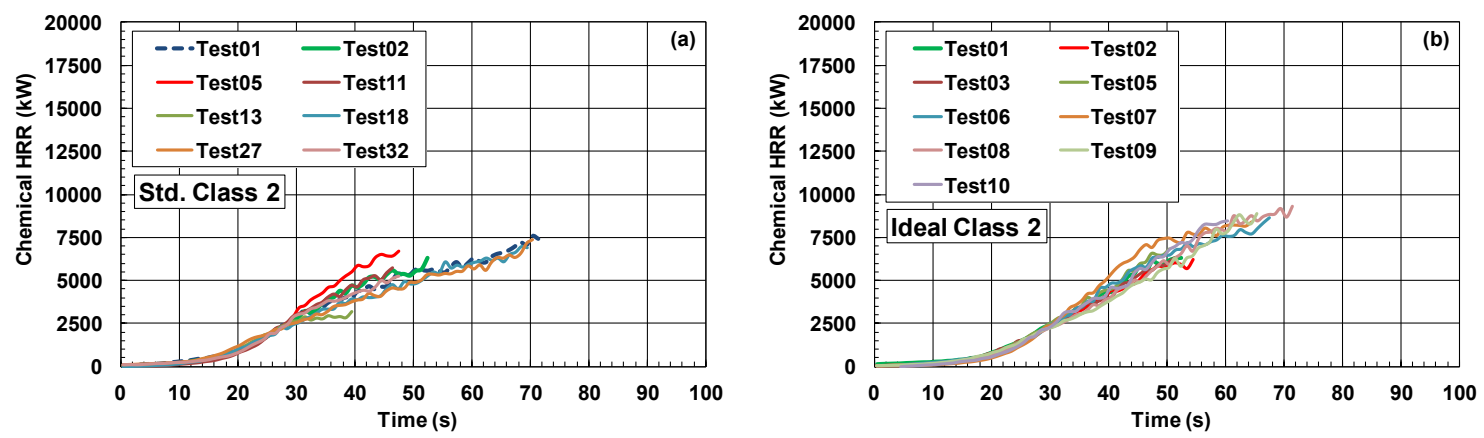

Fig. 7. Fire growth before water application of standard and idealized Class 2 commodities.

After water application, the two commodities exhibit similar responses to the applied water fluxes, i.e., the fires were uncontrolled under $\dot{m}_{w}^{\prime \prime}=4 \mathrm{~mm} / \mathrm{min}$ and controlled under $\dot{m}_{w}^{\prime \prime}=12 \mathrm{~mm} / \mathrm{min}$ (see Fig. 8). Based on these WAA test data, the calculated CDFs for these two commodities differ by about $10 \%$, i.e., 4.40 vs. $4.88 \mathrm{~mm} / \mathrm{min}$. Taking the freeburn and the water application test results together, the idealized Class 2 commodity is a reasonable approximation of the fire hazards of the standard Class 2 commodity. This result not only confirmed the idealized commodity is representative of the real fuel, but also demonstrated the feasibility of simplifying complex fuels, such as cardboard boxes on wood pallets, using rather simple geometry and material properties that are amenable to numerical simulations.
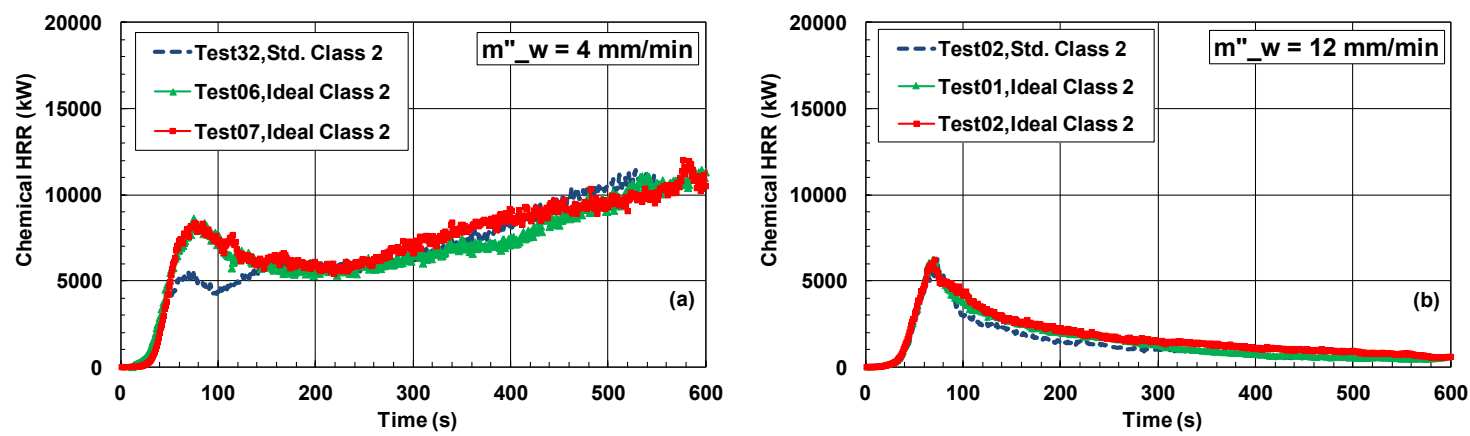

Fig. 8. Fire development under different water fluxes of standard and idealized Class 2 commodities. 


\section{SUMMARY AND FUTURE WORK}

A series of fire suppression tests was conducted using IC2 commodities in a rack storage configuration under uniform water fluxes. In addition to the fire suppression tests, water collection tests under no fire conditions were carried out to obtain baseline data of water transport in rack storage configurations. These tests were aimed at gaining a better understanding of fire suppression using sprinklers and providing experimental data for numerical model validation.

The IC2 commodities were supported within the rack by steel beams. The uniform water fluxes were generated by the WAA, and adjusted to achieve uncontrolled and controlled fire scenarios. The fire development during the WAA tests was characterized by chemical HRR measurements. Thermocouples and plate thermometers were used to monitor fire growth before water application. After the uniform water flux was applied, the water transport was quantified by collection pans placed below the fuel array.

The experimental results show that:

- The WAA test can provide very repeatable results. The calculated CDF value for the beamsupported IC2 are very close to that of standard Class 2 commodity in the same fuel array. Overall, the test results are suitable for model validation purposes using the simplified, but also realistic fuel.

- The high repeatability of the HRRs obtained under different water fluxes suggests that the overall suppression behavior of the IC2 commodity is not sensitive to local water flow distributions on individual fuel surfaces, which have been shown to be highly non-uniform and, presumably, nonrepeatable [2].

- During the fire suppression process, the measured HRRs appear to be quite sensitive to the applied water fluxes for the beam-supported IC2 commodities. In contrast, the CDF values under two different water application conditions were very close to each other.

- During the fire growth process, the PT measurements show that in the early pre-heating stage of the fire growth, the convective component could be at least as significant as the radiative component. When the fuel surface is fully exposed to flames, however, the radiative component should be dominant. The TC measurements also show similar trends.

- Water collection measurements clearly show that, when the fire is out of control, the fractions of water collected are significantly less than those when the fire is suppressed. Furthermore, the water collected directly below the center fuel stacks where ignition occurred was less than that below the adjacent (end) fuel stacks. These observations suggest that water evaporation from fuel surfaces plays a dominant role in water transport, affecting the suppression performance for given applied water fluxes.

- The IC2 commodity is a reasonable approximation of the original standard commodity. As shown by the comparison of fire growth rates and suppression behaviors, the idealized and standard commodities have about $33 \%$ difference in fire growth, but almost identical response to fire suppression. This result suggests the feasibility of modeling complex fuels by the use of a simplified alternative amendable to numerical simulations.

For future work, the global balance of water transport during fire suppression needs to be characterized. The key is to measure the water evaporation rate during fire tests, which may require new instrumentation, such as absorption-based optical probes. The relative humidity type of instrumentations, although readily available for engineering applications, appear not to be suitable in fire tests, since significant increase in temperature can result in very low relative humidity.

\section{ACKNOWLEDGEMENT}

The author is grateful for Dr. Jaap de Vries, Dr. Yi Wang, Dr. Prateep Chatterjee, Dr. Hong-Zeng Yu, Dr. Christopher Wieczorek, Dr. Sergey Dorofeev and Dr. Francesco Tamanini for many invaluable discussions on the experiments, and would like to thank Dr. Marcos Chaos and Mr. Stephen Ogden for fabricating and calibrating the plate thermometer. All experiments were conducted on the FM Global Research Campus with assistance of its staff, whose contributions are sincerely appreciated. 


\section{REFERENCES}

[1] Xin, Y., de Vries, J., Meredith, K.V., Zhou, X., Thumuluru, S. and Yu, H-Z., "Fire Suppression Physics for Sprinkler Protection," Proceedings of FIRESEAT Symposium, Edinburgh, UK, 2011 pp. 23-36.

[2] de Vries J., Meredith K.V. and Xin, Y., “An Experimental Study of Fire Suppression Physics for Sprinkler Protection," Fire Safety Science - Proceedings of the Tenth International Symposium, International Association for Fire Safety Science, 2010, pp. 429-442.

[3] Meredith, K.V., de Vries, J. and Xin, Y. (2011) "A Numerical Model for Partially-Wetted Flow of Thin Liquid Films," Computational Methods in Multiphase Flow VI, pp. 239-250.

[4] Meredith, K.V., de Vries, J. and Xin, Y. (2013) "A Comprehensive Model for Simulating the Interaction of Water with Solid Surfaces in Fire Suppression Environments," Proceedings of the Combustion Institute, 34: 2719-2726.

[5] Meredith, K.V., Xin, Y. and de Vries J., "A Numerical Model for Simulation of Thin-Film Water Transport over Solid Fuel Surfaces," Fire Safety Science - Proceedings of the Tenth International Symposium, International Association for Fire Safety Science, 2010, pp. 415-428.

[6] Wang, Y., Meredith, K.V., Zhou, X., Chatterjee, P., Xin, Y., Chaos, M., Ren, N. and Dorofeev S.B., "Numerical Simulation of Sprinkler Suppression of Rack Storage Fires," Fire Safety Science - Proceedings of the Eleventh International Symposium, International Association for Fire Safety Science, 2014, accepted.

[7] Xin, Y., and Tamanini, F., "Assessment of Commodity Classification for Sprinkler Protection Using Representative Fuels," Fire Safety Science - Proceedings of the Ninth International Symposium, International Association for Fire Safety Science, 2008, pp. 527-538.

[8] Vincent, B.G., "Effect of Propylene Glycol/Water Solutions on Suppression of Corrugated Cartoned Commodities" Fire and Materials - Proceedings of the 12th International Conference and Exhibition, 2011, pp.649-660.

[9] FM Global Approval Standard, “Approval Standard for Automatic Control Mode Sprinklers for Fire Protection," Class Number 2000, March 2006, FM Approvals LLC.

[10] Krishnamoorthy, N., Chaos, M., Khan, M.M., Chatterjee, P., Wang, Y. and Dorofeev, S.B., "Application of Bench-Scale Material Flammability Data to Model Flame Spread in MediumScale Parallel Panel Test," Proceedings of the Interflam, 2010, pp. 709-720.

[11] Chaos, M., "Idealized Class II Tests," private communication, 2010.

[12] Chaos, M., Khan M.M. and Dorofeev S.B., (2013) "Pyrolysis of Corrugated Cardboard in Inert and Oxidative Environments," Proceedings of the Combustion Institute, 34: 2583-2590. 